\title{
THE QUESTION OF APPLIED ANATOMY
}

\author{
ARTHUR W. MEYER
}

Leland Stanford University

The demand for practical teaching in anatomy, and for the practical, has been an insistent one for decades. Unfortunately the term "practical" was often used as opposed to the scientifie by those who made these demands. All facts which did not have a very patent application were spoken of as abstract, or theoretical even. That the teaching of the scientific could not be of any practical utility, and that the inclusion of the practical relations sacrificed the scientific, were long accepted as truisms by many professed devotees of anatomy. The scientific and the practical were supposed to be mutually exclusive and antagonistic, and necessarily so. That in conjunction with other things such misconceptions did not hasten the advent of scientific anatomy, in this country, is better known to many anatomists than to myself. It is not my purpose to consider here what the effect of this so-called practical teaching and of such vicws has been upon the teaching of anatomy and upon the organization of departments of anatomy. Whatever their effect it is clear to erery one that rapid progress is now being made by a movement of truly national scope, and that the names of the few who initiated this movement will ever be held in grateful remembrance. Perhaps no one will gainsay that the training of the future practitioner of medicine shall be a practical one. Every one recognizes that the prevention and alleviation of suffering are the first duty of the physician. Hence, his interest in those facts which have found direct application is a paramount one. But his attention must not be directed solely and his interests confined exclusively to them. The needs of the hour of the practitioner must not become the alpha and omega of student life, for the purely theoretical and scientific of to-day may perchance be, and often have become, the intensely practical and utilitarian of to-morrow. In spite of the strictures passed upon a great national institution a 
few years ago for the accumulation of what were termed "mere facts." I take it that it lies within the power of no one, be he seer or prophet, to judge or to predict the value of an isolated scientific fact. Of books and men many may be insignificant, but not of facts. These are manifestly such only because of ignorance. As Sherrington well said: "In nurturing science, I would urge that the community cultivates more than mere utility; and even in regard to mere utility, as the fields of knowledge fall ripe under the ceaseless husbandry of the world's thought, those who would join in the great reaping, and not only glean where others reaped before them, must cultivate for themselves."

That it is possible to practice medicine without contributing to the development and advancement of the medical sciences, is not denied. This has received abundant demonstration. Yet who will maintain that it can be done as efficiently? Hence, the future licentiate must be trained for growth. He should have a broader horizon and a more fundamental training than can be obtained by mere familiarity with isolated wellestablished facts and well-tried routine procedures of the day. "It is necessary that the student go forth from his school equipped not only with the present applications of science to disease, but so possessed of the root principles of the sciences adjunct to medicine that he may grasp and intelligently use the further development of scientific medicine after he is weaned from his instruction and the school. That is the way to obtain enlightened progress in professional practice. What truer safeguard can a man have, alone it may be, and isolated from the centuries of knowledge, what truer safeguard can he have against all the pseudo-scientific quackeries of the day, than some real knowledge of the principles of the sciences along whose lines the discoveries of medicine must develop?" (Sherrington) Principles rather than details, then, must guide the practitioner of the future, and biological laws rather than facts must point out the line of attack upon the many new problems with which he will come face to face. The memorizing of Gray, or quiz-compend methods, cannot help him, though they enable him to pass stateboard examinations with the best of marks, or take the highest honors. And regarding honors, was it not Stevenson who said, "Though here and there a Lord Macaulay may escape from school honors with all his wits about him, most boys pay so dearly for their medals that they never afterward have a shot in their locker and begin the world bankrupt?"

The old demand for the practical, however, persists although the student who has become interested in a subject, be it ever so far removed from utilitarian ends, seeks such props no more than the teacher who 
really lives in the field in which he works. This is as true, perhaps truer, of human anatomy than of any other subject. Hence, the necessity for teaching applied anatomy must lie in the requirements of the future practitioner, or the exigencies of the situation, rather than in the necessity for arousing interest in anatomy itself. I have elsewhere expressed myself to the effect that I fail to see why many of the things usually included in this subject should be taught at all in the required work of the curriculum, and that many of the remaining relations can be discussed partly in connection with the work in systematic anatomy, and mainly in connection with topographical anatomy leaving to the surgeon the things that are his. The question besides is one of time and of organization.

There seems to be no consensus of opinion, however, on what shall constitute applied anatomy. At the present it may mean topographical anatomy, partly normal and partly pathological, regional topographical anatomy, surgical anatomy, medical anatomy, or anatomy as related to the whole field of medicine and surgery including the specialtiessometimes called clinical anatomy, or even operative surgery. It is clear, of course, that all these things save operative surgery would be included in the term "clinical applied anatomy." Besides these, there are, of course, the relations of anatomy to the fine arts, like sculpture and painting, to hygiene and the related subjects of physical education, to the industries such as the designing of wearing apparel, furniture, seats, chairs, etc. Indeed, shoes and seats are usually made as though body form were wholly undetermined and indeterminable. With the exception, perhaps, of artistic anatomy, the discussion of these matters might be of more real value to the student than much that is now included in so-called applied anatomy. It is not my purpose, however, to suggest that all the above should be included, save in a purely optional course. Indeed, all I am concerned with at present is that there should be some fairly definite understanding as to how much of this work, and which of it, if any, should be included in the required work of the curriculum.

Any one who has examined the books issued on applied anatomy in the last decade or more, either as first or revised editions, must have been impressed with the fact that most of them deal almost exclusively with surgical applied anatomy and with operative surgery. Consequently, they are suited for the use of the surgeon rather than for that of the student of medicine, and, although we have been assured that "the number of excellent works on applied anatomy is large enough to render the exhaustion of an edition of any one a fair presumption of its fitness 
to survive," it is likely that an excellent book on applied anatomy for the student of medicine is yet to be written. Most of the existing texts are indecd surgical applied anatomies, with a varying amount of operative surgery. By far the best of these books which has come to my attention is the well-known little volume by Sir Frederick Treves, called "Surgical Applied Anatomy." In the introduction to this volume, it is frankly stated, that it "is intended mainly for the use of students preparing for their final examinations in surgery." Unfortunately, mceting the examinational requirements of British students has often been made one of the avowed objects of English textbook writers-may I say it?- since or before the days when Sir Charles Bell, great as he was, wrote on the "relation of arteries to surgical operations, especially for those who dissect and desire to take examinations." While the onus of this may easily be borne by men of such eminence, yet when quiz-compend aims are frankly adopted in writing textbooks, it is time to recall that the requirements of a subject and the standards of medical education, rather than licensure tests should determine the character of books deserving careful consideration, unless, as we do not believe, it still be the object of British medical schools, as it is of some of ours, to train students for tests rather than for life. Moreover, since Treves' "Surgical Applied Anatomy" considers such things as Chopart's, Lisfranc's, Pirigoff's and Symes' amputations, and excisions of the superior and inferior maxilla, and shoulder amputations, it is clear that it should not be used indiscriminately in our schools. If all teachers of applied anatomy, or of anatomy, who use textbooks outlining all manner of major operations in surgery, were men of corresponding standing, we might be content to let the matter rest there. But, naturally, this work often is and probably long will be done by those who are neither experienced surgeons nor anatomists. Hence, while a consideration of the technique of major operations in surgery may be all good and well cnough for students and practitioners of surgery, the rank and file of medical students who according to every one should never attempt these things without careful postgraduate hospital training, cannot profit by them.

It is not my intention to write a review of recent books on applied anatomy, but reference to a few may be of interest. As is customary, anatomical facts of importance to the surgeon only are given. Yet the author of one of these very recent volumes hopes that the detail given will be sufficient "to obviate frequent reference to textbooks of systematic anatomy." Some of the clinical and anatomical facts given in this book include the statements that "trigeminal neuralgia is believed 
to be due to contraction of the dural pocket, containing the ganglion, which is therefore crushed." Pain due to "night startings" is said to be due to "a relaxation, and possibly jorking, of these muscles on sleepsupervening, producing a jarring of the bones on one another, the delicate nerve fibrils which exist in such abundance just under the articular cartilage being crushed." (The italics are the writer's.) This same text also copies a longitudinal section of the spinal column with the cord in situ, in which the latter is represented as large as the bodies of the vertebra. "The mediastinum," we are told, "extends from the sternum to the spine, forming a complete septum between the lungs, and is deflected somewhat toward the left. It is bounded by the diaphragm below, but is open above, while laterally it is bounded by the pleura." The author, evidently being undecided whether the mediastinum is a space or a septum, adopts both conceptions, and then bounds the septum by itself! This book also contains facts so invariable and so essential to the surgeon as that the "nutrient artery of the tibia is the largest in the body," and that "the sacrum is really suspended between the innominate bones by its ligaments." Besides these things, the whole book is carelessly written, quite in contrast to the terse, clear English for which many British textbooks are deservedly known. The student is told, for example, that "When the bladder is much distended the orifice is slightly depressed, while if the rectum be distended it is slightly raised. Normally, it lies behind and slightly below the level of the upper margin of the symphysis pubis." Were it not for the many able and eminent surgeons both here and abroad who repudiate such teaching, one might be tempted to suggest that, while such anatomical facts may suffice for the surgeon and for those preparing to pass British licensure tests, any one worthy of the name anatomist would be unwilling to teach them. It is also difficult to see how a novitiate in practice without first-hand experience gained at the operating table, can profit by such descriptions as the following: "Amputations of the shoulder may be performed by making a racket-shaped incision to include a deltoid flap from the outside of the coracoid down to the lower border of the pectoralis major, then outwards across the limb through the lower portion of the deltoid to the posterior axillary fold, the limb being abducted and rotated outwards. As the first part of this incision is practically that for excision, it enables the condition of the parts about the joint to be examined before proceeding to amputate, in case of doubt. The racket is now completed across the superficial tissues on the inner side of the limb. The deltoid flap, containing the posterior circumflex vessels and circumflex nerve, is now 
raised, the capsular muscles, capsule and triceps tendon divided; and the head disarticulated. The triceps, latissimus dorsi, and teres major, are next cut, and the limb being drawn from the side, the axillary vessels may be. ligatured, and then along with the nerves, cephalic vein, humeral branch of the acromio-thoracic artery, some fibers of the deltoid and triceps and coraco-brachialis, divided by a transverse incision." Put this into the hands of the recent graduate, with or without a word about the conditions which justify it, and submit your shoulder, if you like, my friend. This same text gives a similar account of Kraske's operation for carcinoma of the rectum, etc., and, since it does not profess to be an operative surgery, it may pertinently be asked of what use such things are save to enable students to pass examinations which they should not pass, and perform operations which they should never perform.

The purpose of another recent book is "to provide the student with a handbook dealing not only with surgical and medical anatomy but with operative surgery." Hence the fact that "two classical operations seldom performed nowadays have been allowed to remain on account of their historical interest" is not to be wondered at. No doubt gynæcologists as well as anatomists will commend the author of these volumes for concluding that "the surgery of the female generative organs has now become so large a subject that it has been thought possible to omit descriptions or gynæcological operations altogether in the present edition." Even with this omission, it is to be doubted whether American medical students or their future patients can be benefited by instruction which considers iridectomies and cataract extraction, even were this instruction to be given in surgery rather than in applied anatomy.

An attempt has also been made by an American surgeon to bring together what he considers of interest to all medical students. The aim is a worthy one, and we hope that ere long a textbook of applied anatomy, not an operative surgery, will be written by some one fully qualified to do it. In this connection it may be recalled that some textbooks of systematic anatomy retain chapters on practical considerations, much after the manner of Gray. The reason given in Gray, however, for including a large amount of surgical anatomy, was that it was hoped to meet the needs of the practitioner in surgery and not the rank and file of medical students. In an American textbook of systematic anatomy, the high character of which has received well-merited recognition, in spite of the great need for revision, practical relations are also discussed to illustrate "the dependence of diagnosis and practice upon anatomical knowledge, to awake interest and to combat the tendency to regard anat- 
omy as something to be memorized during student days and to be forgotten when examinations are over," and because it was thought "that it will make it easier for the student to learn his anatomy and for the physician to remember and apply it." Whatever one may think of the wisdom of introducing these things, or their efficiency in accomplishing the ends declared, every one certainly recognizes the worthiness of the aims.

There seems to be practical unanimity regarding the demand that students of medicine shall at least satisfactorily dissect the lateral half of the human body. Although this is an absolutely fixed quantity, yet, as every one knows, it is covered in a period of time varying from two hundred to four hundred hours or more. The amount of time spent by the student varying as a rule inversely with the ability of the student and the standing of the school. It is also true that the amount of time required of the student for this work in some of our best medical schools is no criterion of the amount of time actually spent by him. For as long as well-qualified students only are admitted, high standards of work are set and maintained, and sufficient time is reserved in the schedule with or without the introduction of the elective principle, it matters not how much or how little is demanded. As has been well shown, under these conditions, good students do much more than is required of them, while the weaklings who slight their work are easily eliminated by a process of daily supervision and by means of practical instead of memory-test examinations. The other extreme in this matter is represented by the pooriy prepared student who often under adverse conditions rushes through his dissections, oblivious of the fact that one of the chief objects of dissection is to reveal, not to destroy. He often finishes his laboratory work in a few months, and then spends the rest of the year memorizing quiz-compends, studying state-board questions, and taking turns with his teacher in reciting somebody's notes on the subject.

Granted that this minimum requirement has been fulfilled in one way or in another, the question naturally arises whether anything more is desirable as part of the required work of the curriculum. The Committee on Anatomy of the Council of Education of the American Medical Associations, and the Committee of the Association of American Mcdical Colleges, both recommend that medical students do more than the required dissection, and that this additional work be done in topographical anatomy, by laboratory and recitation methods. At the present day, unfortunately, topographical anatomy is often converted into surgical applied anatomy, and taught entirely out of some such text-hook 
as above referred to. This is, of course, as unjustifiable as it is undesirable and unfortunate and it is to be hoped that ere long more laboratories in this country will be properly equipped for work in topographical anatomy. If time or circumstances preclude covering the whole of the the body, let the work be confined to regional topographical anatomy, and combine with this laboratory and class work, in which practical relations in general, and such special relations only as can be understood without a knowledge of pathological and surgical conditions are considered. For if it must be a choice between doing much badly and little well, let the preference always be given to the latter. The laboratory can and should supply frozen and dissected sections in all planes, of both sexes and in all ages. The clinic can supply the living individual when needed, and the lecture to a small extent, and mainly the recitation - or better the colloquium-can furnish the occasion for mutual consideration instead of routine drill. Assuredly, topographical anatomy so presented is a wholly different thing from applied anatomy as usually taught. 